Article

\title{
A Supervised Approach to Delineate Built-Up Areas for Monitoring and Analysis of Settlements
}

\author{
Oliver Harig ${ }^{1, *}$, Dirk Burghardt ${ }^{2}$ and Robert Hecht ${ }^{1}$ \\ 1 Leibniz Institute of Ecological Urban and Regional Development, Weberplatz 1, 01217 Dresden, Germany; \\ r.hecht@ioer.de \\ 2 Institute for Cartography, Dresden University of Technology, 01069 Dresden, Germany; \\ dirk.burghardt@tu-dresden.de \\ * Correspondence: o.harig@ioer.de; Tel.: +49-351-467-90; Fax: +49-351-467-9212
}

Academic Editors: Martin Behnisch, Gotthard Meinel and Wolfgang Kainz Received: 30 April 2016; Accepted: 29 July 2016; Published: 6 August 2016

\begin{abstract}
Monitoring urban growth and measuring urban sprawl is essential for improving urban planning and development. In this paper, we introduce a supervised approach for the delineation of urban areas using commonly available topographic data and commercial GIS software. The method uses a supervised parameter optimization approach along with buffer-based quality measuring method. The approach was developed, tested and evaluated in terms of possible usage in monitoring built-up areas in spatial science at a very fine-grained level. Results show that built-up area boundaries can be delineated automatically with higher quality compared to the settlement boundaries actually used. The approach has been applied to 166 settlement bodies in Germany. The study shows a very efficient way of extracting settlement boundaries from topographic data and maps and contributes to the quantification and monitoring of urban sprawl. Moreover, the findings from this study can potentially guide policy makers and urban planners from other countries.
\end{abstract}

Keywords: settlement boundary; land take monitoring; automation; GIS; spatial planning

\section{Introduction}

A sustainable handling of land is one of the guiding principles of spatial planning. Land is one of the most important resources for recreation but also the production of food and feed as well as bioenergy or biomass and a number of other ecosystem services. Nevertheless, suburbanization leads to ongoing land take and associated urban sprawl. The negative side effects of urban sprawl are, for example, loss of valuable soils, higher infrastructure costs and traffic proliferation.

Therefore, quantification, monitoring and evaluation of land-use changes including their impact is important in order to develop policy goals [1] and evaluate the impact of planning instruments [2]. In European countries, different quantitative targets for reducing land consumption are implemented [3]. For example, Germany aims to reduce daily land take to 30 hectares per day, whereas Great Britain has set the target that $60 \%$ of new housing should be on brownfield land.

In order to quantify land take, the geometric boundaries of settlements are absolutely necessary. However, the definition of a settlement boundary is often difficult. Especially in rural areas, the boundaries between the built-up area and the open space are often fuzzy. The delineation of settlement boundaries is therefore a common challenge in monitoring urban development and measuring urban sprawl. The boundary defines the border between the built-up area (of urban and rural settlements) and the open space. However, this geometry is also important for other applications such as visualization, navigation, generalization, population mapping, etc.

Several groups of researchers have worked on a method for an automated delineation of settlement boundaries. Zhou [4] gives an overview on different approaches with varying data used 
(e.g., census data, remote sensing data, settlement and building data, road network data or volunteered geographic information). Approaches based on remote sensing imagery are very popular as this technology offers an efficient way of mapping fast-growing urban agglomerations. Many approaches are based on classification methods using spectral information from satellite data [5-7]. More recent approaches analyze nightlight data [8]. In contrast to the raster-based methods, there are also approaches proposed that aim for aggregation of vector data. Walter [9] analyzes the density and layout of road networks to define settlement boundaries. Zhou [4] evaluates density-based, intersection-based and street block-based approaches for delineating built-up areas based on road networks. Others aggregate buildings to groups or parts of settlement. Hangouët [10] focuses on grouping of buildings along roads using thiessen polygons and structural data. Regnauld [11,12] uses minimum spanning tree and proximity graphs for typification. He then analyzes their structure in compliance with the criteria of gestalt theory by Wertheimer [13]. Wertheimer defines "principles of grouping" like proximity, similarity, closure, continuity or common fate. Boffet and Serra [14] detect clearances in settlements through the use of building buffers. Then, they use the algorithm developed by Regnauld [11] to form groups of buildings and set them in relation to the detected free spaces. Starting from the road axes, Christophe and Ruas [15] construct perpendicular lines through the centers of building footprints. Following this, perceptual criteria such as proximity, shape, size and orientation were used to derive the building alignments. Yan, Weibel and Yang use a multi-parameter approach to group buildings [16]. Only scant research work has investigated the generalization of building footprints to delineate entire settlement boundaries. Li et al. [17] also group buildings, but they merge and generalize these groups in several steps until they are reduced to an outline of the settlement. They also use thiessen polygons and the rules of gestalt theory. Chaudhry and Mackaness [18] create settlement boundaries with a multi-stage approach directly from building footprints. They use an urbanity index to determine the amount of buffering of a single building. The buildings, which now overlap, are aggregated into a geometry and gaps depending on their size. Small aggregates are eliminated. The resulting geometry is used to select building footprints from the input data set for delineation of the settlements.

The delineation of a settlement may vary strongly in shape depending on the underlying application. The proposed approach presented in this paper is carried out for the special purpose of supporting monitoring of land take and urban sprawl in Germany.

\section{Problem Definition}

In 2002, the German federal government adopted its first sustainability strategy titled "Perspectives for Germany" [19]. One of the strategic goals is to reduce the rate of conversion of non-urban to urban land uses from 130 hectares per day in 2000 to 30 hectares per day in 2020 . In addition, the European Commission explicitly understands land and soils as a resource and sets the aim to achieve zero land take by the year 2050 [20]. To achieve such a policy goal, strategies for the targeted development of the inner zones of cities and towns have been elaborated. Developments should take place in the inner zones (infill development) as a priority and not in the outer zone (greenfield development) where provision of technical and local public infrastructure is not already secured. Hence, the Federal Government [19] defined a ratio of 3:1 for infill development to greenfield development. On the other hand, effective approaches to quantify land take and urban sprawl are needed [21]. Settlement boundaries that are automatically generated from topographic data can contribute to the challenge of measuring land take in high resolution

In contrast to $\S 35$ of German Federal Building Code (BauGB), where the outer zone beyond the boundaries of the city or own is defined, there is no clear definition of the inner zone. In $\S 34$ BauGB, there is a circumscription, in accordance to which it is allowed to develop new building projects beyond legally binding land-use plans. This one is in general understood as inner zone or the build-up area of a settlement with some specific constraints. Thus, for example, an area must display a pattern of connected development and be recognizable as part of a community [22] (§ $34 \mathrm{Rn} 2-6$ ) or buildings 
have to be suitable as long-term living quarters for people [23] ( $\$ 34 \mathrm{Rn} 7)$ to be part of the inner zone. It aims at the organic growth of settlements and at preventing urban sprawl.

However, the precise delineation is always an individual decision in planning practice. In order to evaluate national and European policy targets objectively, a common definition of the inner zones (built-up areas) is necessary. In Germany, there are no nation-wide data on available inner zones. In several research projects, a settlement geometry called "Ortslage" which might be translated as "settlement bodies" was taken from the Digital Landscape Model from the Authorative Topographic-Cartographic Information System (ATKIS ${ }^{\circledR}$ Base DLM) [24] (p. 35), [25] (p. 9). The geometry covers, beside residential areas, industrial and commercial areas, areas of mixed use, and areas of particular functional characteristics, also the areas of traffic, water bodies, areas occupied by buildings and other facilities for recreation, sports and leisure activities as well as vegetation areas with a close spatial and functional connection [26]. With the very broad interpretation of the settlements under "Ortslage", however, this is only a very rough approximation for inner zones, as discussed in Schiller et al. [27].

On the other hand, in recent years, several algorithms for an automatic delineation of built-up areas have been developed in the context of cartographic generalization. The delineation of built-up areas is primarily used in topographic maps where due to small scales the representation of single buildings is no longer possible [18]. An example is the "Delineate Built-Up Areas" tool implemented in ArcGIS for Desktop (Version 10.2 and higher) [28]. Its applicability, however, has not yet been studied in the context of monitoring purposes. This leads to the question of whether such standard generalization tools are able to automatically delineate inner zones with reasonable accuracy. Therefore, this paper examines different aspects of parameterization, achievable accuracies and associated errors. Furthermore, we try to clarify whether an automated settlement delineation using commonly available topographic data is better than the often-used "Ortslage" geometry from the ATKIS ${ }^{\circledR}$ Base DLM.

\section{Method}

The following section gives a short overview of the approach as well as detailed explanations of the major parts.

\subsection{Workflow}

Figure 1 shows how the individual process sections are coupled to each other. In a first step, cartographic partitions of the study area are created on basis of building footprints. These topographic partitions help to reduce the data volume for the processing but are also used to divide reference data into a training data set and a test data partitions for the later performed k-fold cross validation (CV). In machine learning, cross validation is used to estimate the generalization error [29] (p. $486 \mathrm{ff}$ ). In this case, the data are divided in k=10 partitions; nine of these are used for training and one for testing. The training and testing is repeated 10 times so that every subsample is once used for testing.

The main component is the delineation process where different process variants of a delineation algorithm are tested against each other. This step includes the parameter optimization using a predefined quality measure. It requires the building footprints, reference data and, when applicable, auxiliary data such as the road network data. The defined process variants vary in their complexity and may include pre- and post-processing steps. A more detailed description of the variants tested in this study can be found in Section 3.2.

The procedure to get the optimized settlement boundary for each process variant is as follows: At first, the algorithm is applied to the each CV-partition of the training data set by varying their model parameters. In this process, a best parameter combination is determined using the defined quality measure. Further, the best obtained parameter combinations are tested against the test data (CV-partitions) by computing the quality measure values. All of the calculated quality measures from 
the 10 test data partitions are stored in a database. Finally, the set of parameters with the highest quality value is determined. The single processing steps are presented in detail below.

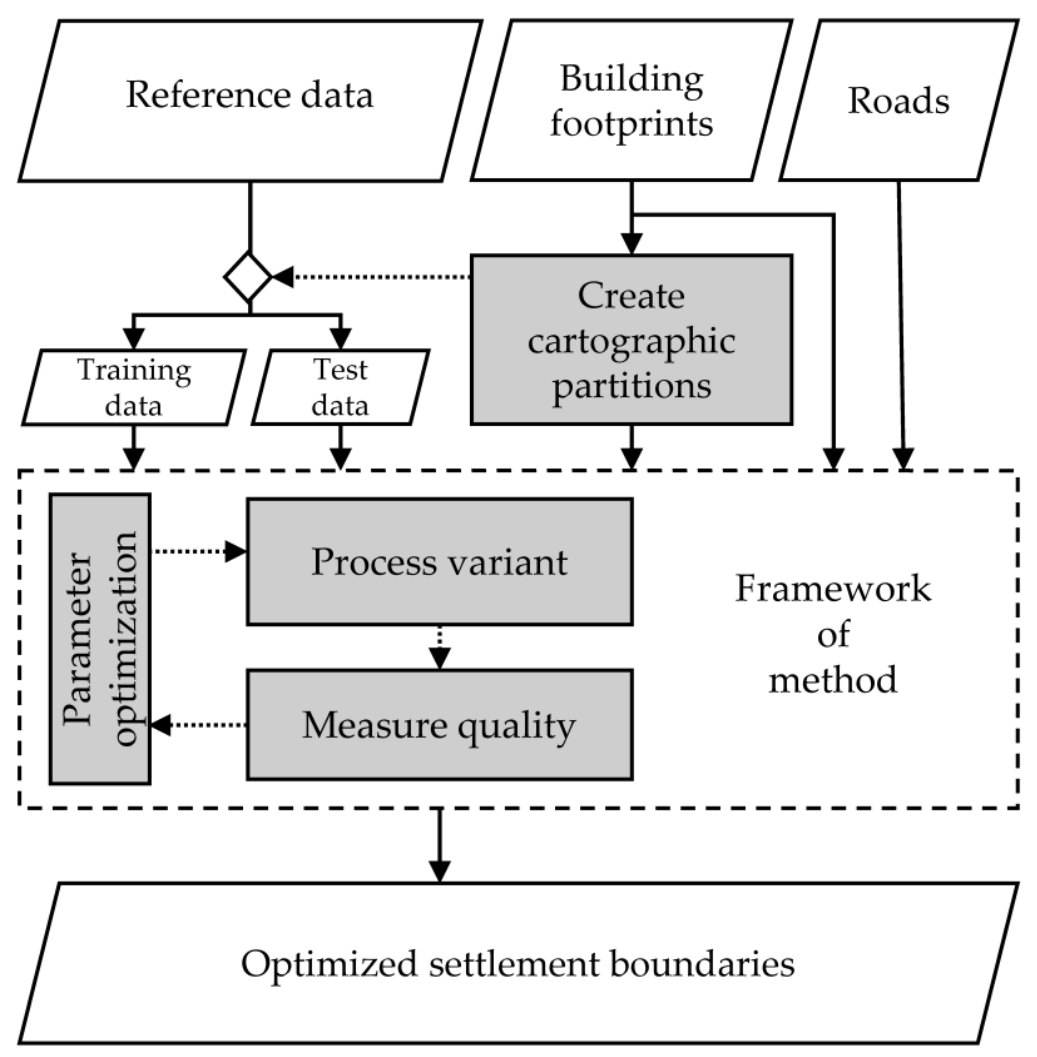

Figure 1. Process chart.

\subsubsection{Create Cartographic Partitions}

The model is designed to delineate built-up areas for regions or entire states. Building footprints data can easily contain millions of objects. For very complex and computationally intensive algorithms, it may be necessary to divide the data into smaller parts. This is, in context with large data sets and the associated computational effort, a common method. Furthermore, the resulting geometry is later on used as input for the random sampling in the cross validation process. It is important to ensure that the partitioning fits to the content to prevent secondary effects (e.g., inadequate splitting of settlement bodies). Municipal boundaries are partially too coarse or the geometry may split larger settlement bodies inappropriately (e.g., two connected villages along a road). Therefore, we create own cartographic partitions based on building data.

In a first step, a density raster map is calculated analyzing the building footprints. In this process, each resulting cell represents a density value. The density value $d$ of a cell is calculated by the division of the sum of lengths of all lines $L$ within a circle (radius $r$ ) around the cell center and the area of this circle (cf. Equation (1)). This density function is implemented in ArcGIS for Desktop by default [30]. The grid cell size must be determined according to the application. A grid spacing of $100 \mathrm{~m}$ and a radius of $200 \mathrm{~m}$ has been proven to be useful for different kinds of settlements in our study area (cf. Figure $2 b$ ).

$$
d=\frac{\sum_{k=1}^{n} L_{k}}{\pi * r^{2}}
$$

Next, the raster map is converted into a point raster, where each point contains an attribute with the corresponding density value of the cell. All points below a threshold value (density value $<0.0009 \mathrm{~m} / \mathrm{m}^{2}$ ) are deleted and only point clusters with high density values will remain. 


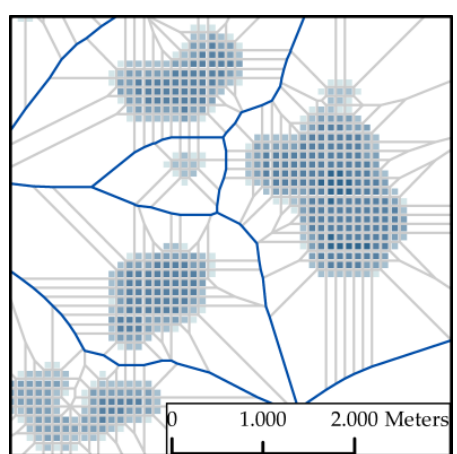

(a)

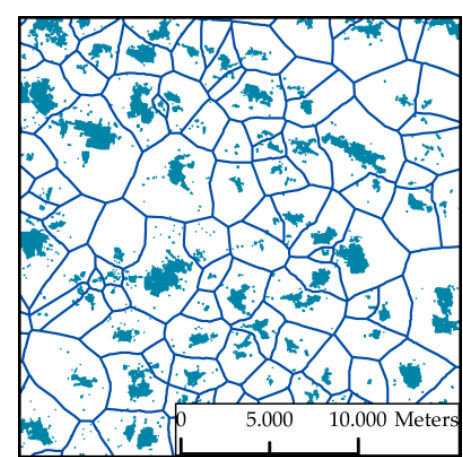

(b)

Figure 2. Cartographic partitioning process: (a) Voronoi diagram (grey lines) and the remaining meshes (dark blue lines) in the density map; and (b) original buildings (turquoise) and boundaries of the final cartographic partitions (dark blue lines).

The threshold was set by empirical testing. Subsequently, a triangulated irregular network (TIN) and a Voronoi diagram is generated (cf. Figure 2a), which forms a regular pattern within the remaining point clusters. Starting from the Voronoi diagram, all lines of equal length to the defined cell size of the density map and all lines with a dead end are deleted. The remaining lines (dark blue lines in Figure 2a) form meshes that are converted into polygons (cf. Figure $2 b$ ). In our experimental study, only those partitions are relevant that overlap the reference data.

\subsubsection{Parameter Optimization}

Automatic parameter optimization and the definition of constraints are important for the development of efficient workflows in the automatic generalization of geospatial data. Choosing the right parameters of a delineation algorithm via "trial and error" will work to a limited extent only and is time consuming. With an increasing size of the area under investigation, this approach reaches its limits due to the vast heterogeneity of settlements in size and shape.

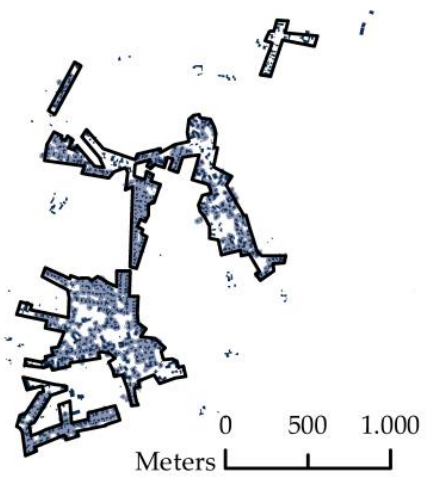

(a)

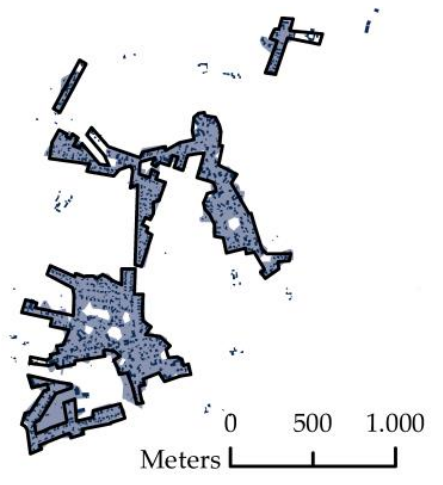

(b)

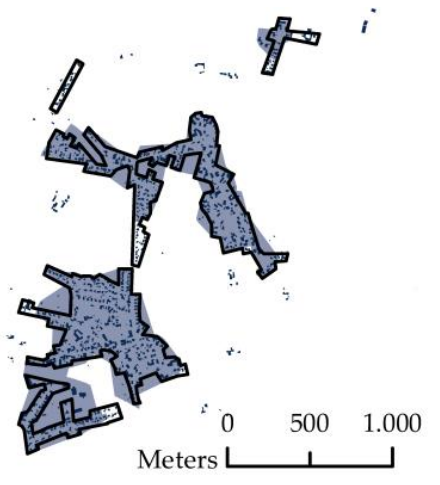

(c)

Figure 3. Examples of different aggregation levels by using different parameter combinations $\left(\mathrm{P}_{1}\right.$ and $\left.\mathrm{P}_{2}\right)$. Automatic delineation (blue areas) in comparison to a reference geometry (black lines) (Official building polygons, ATKIS ${ }^{\circledR}$ Base-DLM@ Geobasis-DE/BKG (2011)): (a) $\mathrm{P}_{1} 10 / \mathrm{P}_{2}$ 10; (b) $\mathrm{P}_{1} 40 / \mathrm{P}_{2} 40$; and (c) $\mathrm{P}_{1} 70 / \mathrm{P}_{2} 100$.

In this step, the parameters of any given delineation algorithm can be optimized with the help of reference data. Figure 3 shows for example how different parameter combinations of a generalization algorithm cause different delineations from highly fragmented and small polygons (Figure 3a) 
to highly aggregated and simplified polygons (Figure 3c). Machine learning helps to determine the best parameter combination by using available reference data. A simple solution is to calculate all combinations of parameters $\mathrm{P}_{1}, \mathrm{P}_{2}, \ldots, \mathrm{P}_{n}$ choosing the one that yields the best results in comparison to a reference (cf. Figure 4).

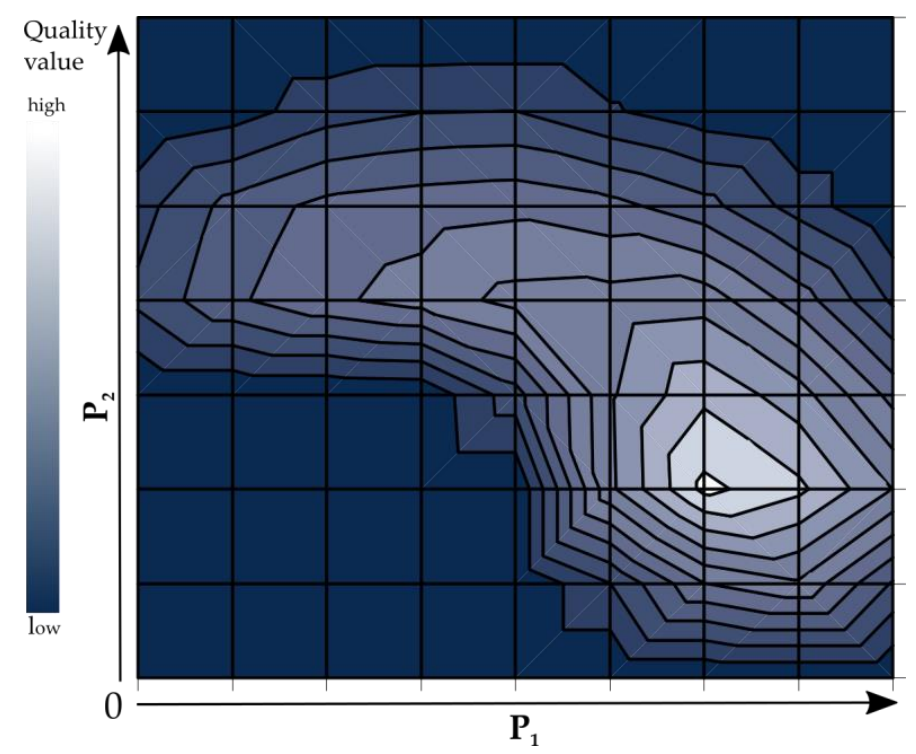

Figure 4. Example of surface chart of resulting quality values at different parameter combinations.

\subsubsection{Definition of a Geometric Quality Measure}

Quality measures in the context of automated generalization can fulfill the three tasks formulated by Mackaness and Ruas [31]: evaluation for tuning, evaluation for controlling the generalization process during generalization and evaluation for assessing the quality of generalized data after generalization. We used them for all of these purposes.

For quality measurement, we use an adaptation of the buffer overlay statistics method (BOS) introduced by Tveite and Langaas [32]. To avoid confusion, the adapted method used here is referred to as Buffer Overlay Method (BOM). Basically, the BOM uses intersection of polygons generated by buffering the boundaries. This works for boundary lines of the reference $R$ and the outline $D$ of the generated built-up area as well as those generated by buffering the resulting polygons (Area $(R B)$, Area $(D B))$ and intersection (Area $(R B \cap D B)$ ). The quality value $Q_{B O M}$ is calculated from the ratio of the area that is created by buffering and overlaying the two boundaries $(A r e a(R B \cap D B)$ and the area of the buffered reference boundary $(\operatorname{Area}(R B))$. Equation (2) shows the calculation of the quality value $Q_{B O M}$ :

$$
Q_{B O M}=\frac{\operatorname{Area}(R B \cap D B)}{\operatorname{Area}(R B)}
$$

The buffer width has to be set according to the application and the used data. In our approach, we use a buffer width of $15 \mathrm{~m}$. For example, in this case, an average distance between the reference and the delineation of $15 \mathrm{~m}$ is equal to a $Q_{B O M}$ value of 0.5 , due the overlap half of the buffered area forms part of the reference area.

\subsection{Processing Variants}

In our study, we use various processing variants that all based on the "Delineate Built-Up Area" out-of-the-box functionality available in Esri's ArcGIS for Desktop (Version 10.4). This standard tool is part of the generalization toolset and has been used to identify dense settlement arrangements in the context of cartographic generalization [33]. Therefore, it is assumed that this tool is also suitable for 
the delineation of inner zones. Although the tool is a black box, according to the documentation [28], the tool outlines densely clustered buildings and creates polygons representing built-up areas. Dense arrangements of buildings are defined by the Grouping Distance parameter (GPR). The outline of the resulting polygons can be snapped to other features like roads or railways. However, only features within the grouping distance and in the same direction of the polygon are snapped. The complexity of the resulting polygons is controlled with the Minimum Detail Size parameter (DET). The relevant tool parameters are summarized in Table 1.

Table 1. Description of the parameters of the "Delineate Built-Up Area" tool (taken and revised from [28]).

\begin{tabular}{cc}
\hline Parameter & Explanation \\
\hline Input polygons & $\begin{array}{c}\text { As input polygons we use building footprints. Their density and arrangement } \\
\text { are used to define appropriate built-up polygons as output. }\end{array}$ \\
\hline Output polygons & $\begin{array}{r}\text { The output contains polygons of built-up area representing } \\
\text { clusters of input buildings. }\end{array}$ \\
\hline Grouping Distance (GRP) & $\begin{array}{c}\text { Buildings that are closer together than the grouping distance are grouped } \\
\text { together. The grouping distance is measured from the edges of building polygons } \\
\text { to the center points of the buildings. }\end{array}$ \\
\hline Minimum Detail Size (DET) & $\begin{array}{c}\text { This value defines the relative degree of detail in the output polygons. This } \\
\text { roughly corresponds to the minimum allowable diameter of a cavity in the } \\
\text { output polygon. The actual size and shape of cavities within the polygon is } \\
\text { determined also by the arrangement of the input buildings, the grouping } \\
\text { distance, and the presence of auxiliary features, if they are applied. }\end{array}$ \\
\hline Auxiliary data & $\begin{array}{c}\text { This layer is used to define the edges of the output polygons. These snap to an } \\
\text { auxiliary feature if it is generally aligned with the trend of the polygon edge and } \\
\text { lies within the grouping distance. }\end{array}$ \\
\hline Minimum building count (MCB) & $\begin{array}{c}\text { This is the minimum number of buildings that have to } \\
\text { be present to create an output polygon. }\end{array}$ \\
\hline
\end{tabular}

In this approach, only the parameters GRP and DET will be optimized during the training process. The optimization for these parameters has to be carried out in increments with a defined interval that fits the target accuracy. In case of an application scenario for the monitoring of land take, the target scale is 1:10000 up to 1:25000. In regional planning scales of 1:50000 up to 1:100000 are typical. Therefore, increments of $10 \mathrm{~m}$ for the parameters GRP and DET are chosen. Smaller increments are possible, but would deliver only seemingly more information. A starting value of 5 is chosen and gradually raised to a final value of 75 . The third numerical parameter Minimum Count of Buildings $(M C B)$ was to set to a fixed value. With respect to the constraint of a minimum of 10 to 12 buildings to form an inner zone [23] ( $\$ 34 \mathrm{Rn} 111$ ) a value of 15 for $M C B$ was chosen.

In the following, four different processing variations are specified in order to examine the effects of using additional data, pre- and post-processing or data filtering.

\subsubsection{Delineate Built-Up Area Using Building Polygons (DBA-B)}

In this variant, the Delineate Built-Up Area tool is used as it is implemented in the ArcGIS toolbox. Only building polygons are used as input data and no data manipulation (pre- or post-processing) is carried out.

\subsubsection{Delineate Built-Up Area Using Building Polygons and Road Network (DBA-BR)}

In this processing variant, a road network dataset is added as auxiliary data since this is also a common boundary to define built-up areas [22] ( $\$ 34 \mathrm{Rn} 6)$. Features of this dataset within the grouping distance and in the same direction of the polygon are snapped. As a result, the shape of the resulting polygon is adjusted by the layout of the roads. This is an option the tool provides by default. All parameters were set as described above. 
3.2.3. Delineate Built-Up Area Using Building Polygons and Road Network with Additional Pre- and Post-Processing (DBA-BRPP)

In this variant, additional pre- and post-processing steps were performed such as elimination, buffering, simplification or removal of empty spaces. These are common operations in this context [34].

Buildings were removed that cannot be assigned to the inner zone by definition. These are buildings that are not suitable as long-term living quarters for people [22] ( $\$ 34 \mathrm{Rn} 7)$. This concerns, in particular, buildings for agriculture or warehouses, gardens and weekend houses, or sheds and garages. The small and irrelevant buildings can be identified due to their small size. Hecht [35] (p. 156) verified that detached buildings with a footprint size of 56 square meters and attached buildings with a footprint size of 39 square meters have a probability of $99 \%$ that they are not residential buildings. Therefore, all buildings with a footprint smaller than 39 square meters are omitted. The identification of buildings for agriculture is much more difficult. A distinction between these and large commercial buildings, based only on building footprint, is almost impossible.

Further, the remaining building footprints are transformed into minimum enclosing rectangles and buffered depending on length of the smallest edge. If the length of the smallest edge of the minimum enclosing rectangle is smaller than $35 \mathrm{~m}$ and greater than $6 \mathrm{~m}$, the difference to $35 \mathrm{~m}$ is calculated, and the geometry is buffered with this value. In all other cases, building footprints are buffered with $1 \mathrm{~m}$. This buffering ensures a minimum width of the resulting settlement boundary. This step ensures a better delineation of linear structures such as for row housings.

Depending on the control parameters Grouping Distance and Minimum Detail Size, the delineated polygons contain larger or smaller empty spaces (holes in polygons). The assumption is that empty spaces smaller than one hectare in size are part of the settlement and are therefore closed. All other larger empty spaces remain. Additionally, gaps between adjacent polygons within a distance of $50 \mathrm{~m}$ are also closed.

3.2.4. Delineate Built-Up Area Using Building Polygons and Road Network with Additional Pre- and Post-Processing and Urban Index (DBA-BRPPU)

This variant contains an additional filtering process to distinguish between agricultural buildings and large commercial buildings. Here it is assumed that barns and stables are buildings located mainly at the edge of or outside of settlements, usually stand alone and usually have a larger footprint than a residential building in rural areas. For the identification, the urban index by Chaudhry and Mackaness [18] was used for a characterization. The index $U_{j}$ for the building $j$ considers the nearest $n$ buildings (see Equation (3)). The variable $a$ represents the area of the footprint and variable $d$ the shortest distance from the buildings to building $i$. In the model, only the building footprints with a $U_{j}$ value greater than 0.0003297 are used for further processing. The threshold was set with the help of a curve resulting from a Receiver Operating Characteristic (ROC) analysis. In general, such a ROC-analysis is a method to identify an optimal cut point in binary classification problems. In GIS, ROC-analyses are widely used, for example, to predict land use/cover change, species' distribution, disease, and disaster risks [36].

$$
U_{j}=\frac{\sqrt{a_{j}} \sqrt{\sum_{i=1}^{n} a_{i}}}{\sum_{i=1}^{n} d_{i}^{2}}
$$

\section{Results}

In this section, the resulting delineations of each variant are investigated in detail. At first, the data used in this study is explained. Then, the different processing variants are compared in terms of the achieved accuracies by computing different quality measures such as the introduced $Q_{B O M}$ value, classification accuracy as well as precision and recall. Further, the processing variants are compared in terms of the visual impression. Finally, different types of errors are introduced that might be relevant from an application-oriented point of view. 


\subsection{Data and Data Preparation}

As described above, the availability of useful and up-to-date reference data is limited. As reference boundaries, inner zone geometries from the Hannover region could be acquired. They were created in the year 2005 under the Regional Planning Program 2005 (RROP) with the help of experts based on the automatized land survey map (ALK) and orthophotos [37] as a complete inventory of all small towns with fewer than 2000 inhabitants. Therefore, the reference covers only parts of the entire region.

The building footprints are one of the key input data for algorithms for the delineation of settlements. Those can be obtained from different sources such as, topographic databases, maps, remote sensing imagery, LiDAR, etc. In this study, we use the German-wide data product Official Building Polygons (HU-DE) of Lower Saxony from 2011. The HU-DE contains geo-referenced polygons representing building footprints derived from the German real estate cadaster. The polygons do not contain any attributive information with the exception of an Official Municipality Key (in German: Amtlicher Gemeindeschlüssel (AGS)). This dataset is updated every year.

As auxiliary data, street and road line data of the ATKIS ${ }^{\circledR}$ Base DLM from 2011 is used. The dataset includes nationwide all streets, roads, including unpaved roads, if they are important connections between settlements.

The reference dataset has been created for a different purpose. Therefore, adjustments are carried out in a data preparation process. This includes the identification and removal of topology and digitization errors (e.g., overlaps, partial coverages, etc.). After data preparation, the reference data include 166 reference polygons with an average size of 28 hectares. An overview of the data used is provided in Table 2.

Table 2. Overview of input data.

\begin{tabular}{ccccc}
\hline & Topicality & Distribution Agency & Objects & Reference Scale \\
\hline ATKIS $^{\circledR}$-Ortslage & 2011 & NMAs $^{1}$ & 197 & $1: 25,000$ \\
\hline ATKIS $^{\circledR}$-Roads & 2011 & NMAs $^{1}$ & 32.788 & $1: 10,000$ \\
\hline Reference polygons & 2005 & $\begin{array}{c}\text { Kommunalverband } \\
\text { Region Hannover }\end{array}$ & 166 & $1: 1000$ to 1:2000 \\
\hline Official Building Polygons (HU-DE) & 2011 & ZSHH $^{2}$ & 92.080 & $1: 1000$ \\
\hline
\end{tabular}

${ }^{1}$ National mapping agencies; ${ }^{2}$ Central Distribution Agency for House Coordinates, Building Polygons and 3D Building.

\subsection{Comparison of Processing Variants}

The optimized parameter sets are results of the testing. The best values are achieved for boundaries with short edge lengths of $5 \mathrm{~m}$ and a grouping distance of 45 or $25 \mathrm{~m}$ (cf. Figure 5).

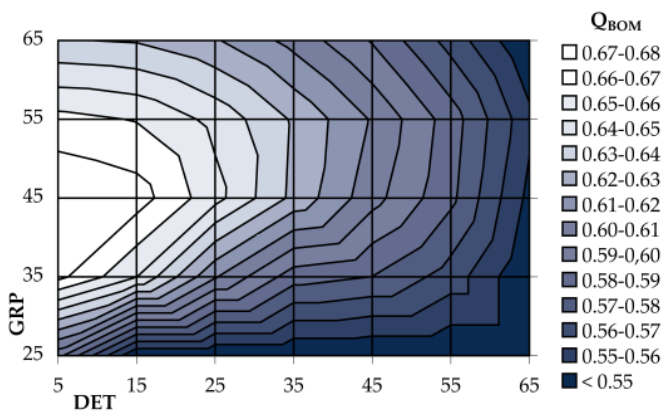

(a)

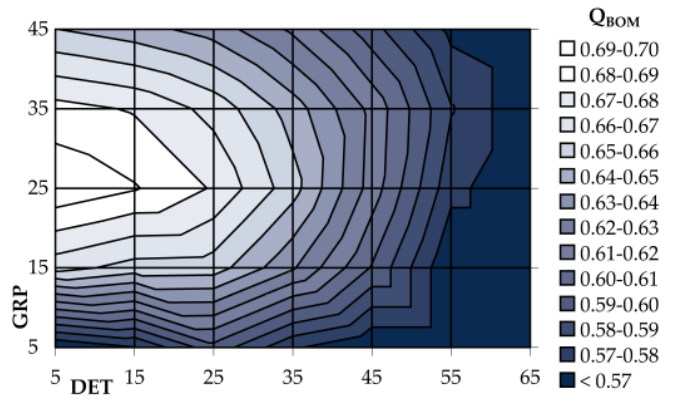

(b)

Figure 5. Surface chart of $Q_{B O M}$ values at different parameter combinations of variant DBA-BR (a); and variant DBA-BRPPU (b). 
During training and testing, the evaluation steps were always performed to the full extent of the delineation. The quality value $Q_{B O M}$ is then calculated for each true-positive single feature. On the basis of this value, statistical characteristics (mean, median, maximum and minimum value, range and standard deviation) are computed. The ATKIS ${ }^{\circledR}$-Ortslage is included for reasons of comparison. The results are shown below in Table 3.

Table 3. Results of the single feature evaluation (Best parameter set DET/GRP; arithmetic mean $\varnothing$, median $\mathrm{m}$, range as difference of Max and Min value and standard deviation $\sigma$ of $Q_{B O M}$ ).

\begin{tabular}{cccccccc}
\hline & Para. DET/GRP & $\varnothing\left(Q_{\text {вом }}\right)$ & $\mathbf{M}\left(Q_{\text {вом }}\right)$ & $\mathbf{R}$ & Мax $\left(Q_{\text {вом }}\right)$ & Min $\left(Q_{\text {вом }}\right)$ & $\boldsymbol{\sigma}\left(Q_{\text {вом }}\right)$ \\
\hline ATKIS $^{\circledR}$-Ortslage & - & 0.615 & 0.617 & 0.560 & 0.885 & 0.325 & 0.114 \\
\hline DBA-B & $5 / 45$ & 0.620 & 0.626 & 0.416 & 0.817 & 0.401 & 0.069 \\
\hline DBA-BR & $5 / 45$ & 0.679 & 0.690 & 0.367 & 0.811 & 0.444 & 0.069 \\
\hline DBA-BRPP & $5 / 25$ & 0.710 & 0.714 & 0.417 & 0.856 & 0.439 & 0.068 \\
\hline DBA-BRPPU & $5 / 25$ & 0.705 & 0.717 & 0.465 & 0.850 & 0.385 & 0.077 \\
\hline
\end{tabular}

The ATKIS ${ }^{\circledR}$-Ortslage shows the lowest values overall. The average $Q_{B O M}$ value is 0.615 . An exception is the Max $\left(Q_{B O M}\right)$. This is found with a value of 0.885 at the ATKIS $^{\circledR}$-Ortslage. The smallest range between best and worst delineation of a single settlement is found in variant DBA-BR with 0.367. The best average quality is reached in variant DBA-BRPP with a $Q_{B O M}$ of 0.710 . In variant DBA-BRPPU, the additional processing step has not improved the quality of the delineation. Here, the $Q_{B O M}$ value is 0.705 . The numerical results are visualized again as boxplots in Figure 6.

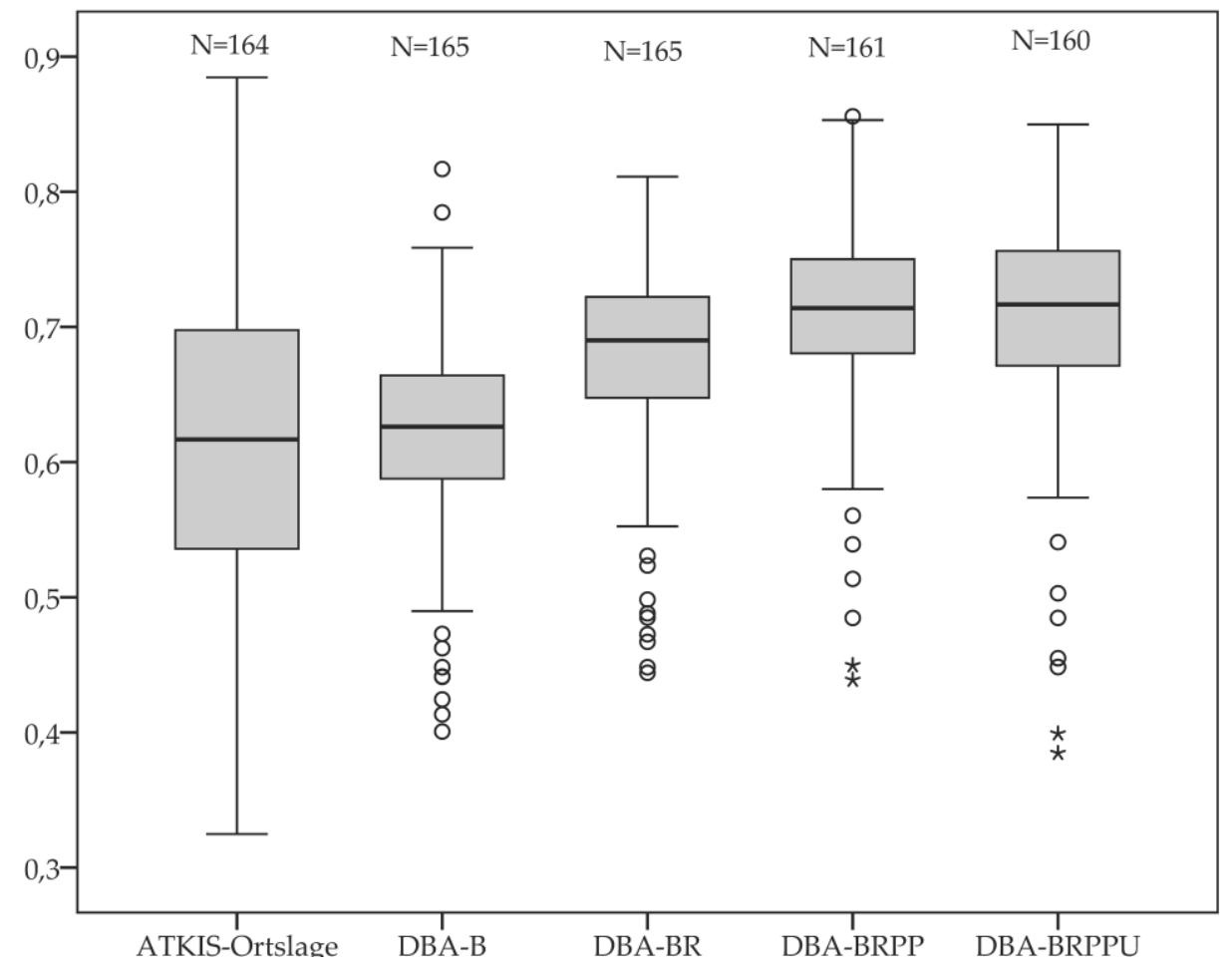

Figure 6. Boxplots of $\mathrm{Q}_{\mathrm{BOM}}$ values for single feature evaluation.

Whether the results differ significantly was also investigated. Significance is confirmed for a $p$-value less than significance level $\alpha=0.05$. For the ATKIS ${ }^{\circledR}$-Ortslage, it was not possible to detect a normal distribution using the Shapiro-Wilk test. In addition, the variance differed greatly from the other approaches. The variance is heterogeneous and ns are unequal. Therefore, the Mann-Whitney test was used for comparisons with this approach and due to the different sample sizes, for the other 
samples the Welch test was used. The results of the tests are shown in Table 4 below. Accordingly, the results of the variants ATKIS ${ }^{\circledR}$-Ortslage and DBA-B as well as the variants DBA-BRPP and DBA-BRPPU do not differ significantly from each other. For all others, significant differences were confirmed.

Table 4. Results of testing significance ( $p$-value).

\begin{tabular}{ccccc}
\hline & DPA-B & DPA-BR & DBA-BRPP & DBA-BRPPU \\
\hline ATKIS $^{\circledR}$-Ortslage & $0.650^{1}$ & $0.000^{1}$ & $0.000^{1}$ & $0.000^{1}$ \\
DBA-B & & $0.000^{2}$ & $0.000^{2}$ & $0.000^{2}$ \\
DBA-BR & & & $0.000^{2}$ & $0.002^{2}$ \\
DBA-BRPP & & & & $0.567^{2}$ \\
\hline
\end{tabular}

${ }^{1}$ Mann-Whitney test; ${ }^{2}$ Welch test.

\subsection{Precision and Recall}

In Table 5, the classification results with a view to the whole settlement are shown. If a delineation is generated by the algorithm at the location at which a reference boundary exists, this is counted as a true-positive (TP) classification. Accordingly, a false-negative classification (FN) is then applicable when a reference boundary exists and no delineation was created by the algorithm. A false-positive classification (FP) results when a delineation has been created, but there is no corresponding reference boundary. The classification accuracy can be illustrated by precision and recall. Precision is the fraction of the true-positives (TP) and the sum of the TP and false-positives (FP), while recall means the fraction of TP and the sum of TP and false-negatives (FN). Variant DBA-BRPP $(0.96 / 0.97)$ and DBA-PRPPU $(0.97 / 0.96)$ have the highest values for precision and recall (cf. Table 5).

Table 5. Number of true positive (TP), false positives (FP) and false negative (FN) classified settlements.

\begin{tabular}{|c|c|c|c|c|c|}
\hline & $\mathbf{N}_{\text {TP }}$ & $\mathbf{N}_{\mathrm{FN}}$ & $\mathbf{N}_{\mathbf{F P}}$ & Precision & Recall \\
\hline ATKIS ${ }^{\circledR}$-Ortslage & 164 & 2 & 17 & 0.91 & 0.99 \\
\hline DBA-B & 165 & 1 & 48 & 0.77 & 0.99 \\
\hline DBA-BR & 165 & 1 & 47 & 0.78 & 0.99 \\
\hline DBA-BRPP & 161 & 5 & 7 & 0.96 & 0.97 \\
\hline DBA-BRPPU & 160 & 6 & 5 & 0.97 & 0.96 \\
\hline
\end{tabular}

In Table 6, the classified areas are quantified. The area of the reference, the area of delineation, true positive (TP), false positives (FP) and false negative (FN) classified area is calculated as well as precision and recall. The ATKIS ${ }^{\circledR}$-Ortslage has the highest TP-value with 4403 ha, but also the highest classification error with 1570 ha $(\mathrm{FN}+\mathrm{FP})$. Variant DPA-BRPP is second on TP area with 3823 ha. However, the overall classification error is the smallest with 867 ha (FN+FP).

Table 6. Area of reference, delineation, true positive (RP), false positives (FP) and false negative (FN) classified area in hectare.

\begin{tabular}{cccccccc}
\hline & Area Ref. & Area Deli. & Area (TP) & Area (FN) & Area (FP) & Precision & Recall \\
\hline ATKIS ${ }^{\circledR}$-Ortslage & 4683 & 5973 & 4403 & 141 & 1.429 & 0.75 & 0.97 \\
DBA-B & 4683 & 4016 & 2735 & 975 & 307 & 0.90 & 0.74 \\
DBA-BR & 4683 & 4468 & 3417 & 634 & 417 & 0.89 & 0.84 \\
DBA-BRPP & 4683 & 4690 & 3823 & 430 & 437 & 0.90 & 0.90 \\
DBA-BRPPU & 4683 & 4569 & 3682 & 501 & 386 & 0.91 \\
\hline
\end{tabular}




\subsection{Visual Analysis of Variants}

Figure 7 provides a visual impression of the ATKIS ${ }^{\circledR}$-Ortslage as well as the four best delineations of individual variants. Many large areas with false-positive classifications can be recognized in the ATKIS ${ }^{\circledR}$-Ortslage. These areas can assume significantly greater proportions when settlements include areas for leisure and recreation (e.g., sports fields, and parks) or allotments. Sports facilities and parks contain typically very few buildings. These areas disappear with the building-based delineation approach. Therefore, in variant DBA-B, only a few false-positive classifications are visible, but the delineation includes a plurality of empty spaces. These reflect the high false-negative values from Table 6. The main difference between variant DBA-B and DBA-BR is that the layout of the streets is taken into account. This cannot be seen in the illustration, since there are only adjustments to a few meters. However, consideration of the sum (cf. Tables 3 and 6) reveals a significant increase of accrual quality. In variants DBA-BRPP and DBA-BRPPU, the building footprints were pre-processed as described in Section 3.2.3 and the delineations were reworked. Because of the elimination of single buildings in settlement bodies with very few buildings, the minimum number of buildings is not reached or the distance between the remaining buildings (MBC) is too large to form a polygon. In Figure $7 d$,e, this is visible in the false-negative classification of settlement 1 . The closing of empty spaces and gaps decreases false-negative classifications. However, in the marginal region there are still individual buildings, resulting in false-positive-classifications. Therefore, in variant DBA-BRPPU, an additional filter is included, the urbanity index. However, a secondary effect of deleting more buildings is that there are more false-negative classifications, as seen in Figure 7e in comparison to Figure $7 \mathrm{~d}$ as well in Table 6.

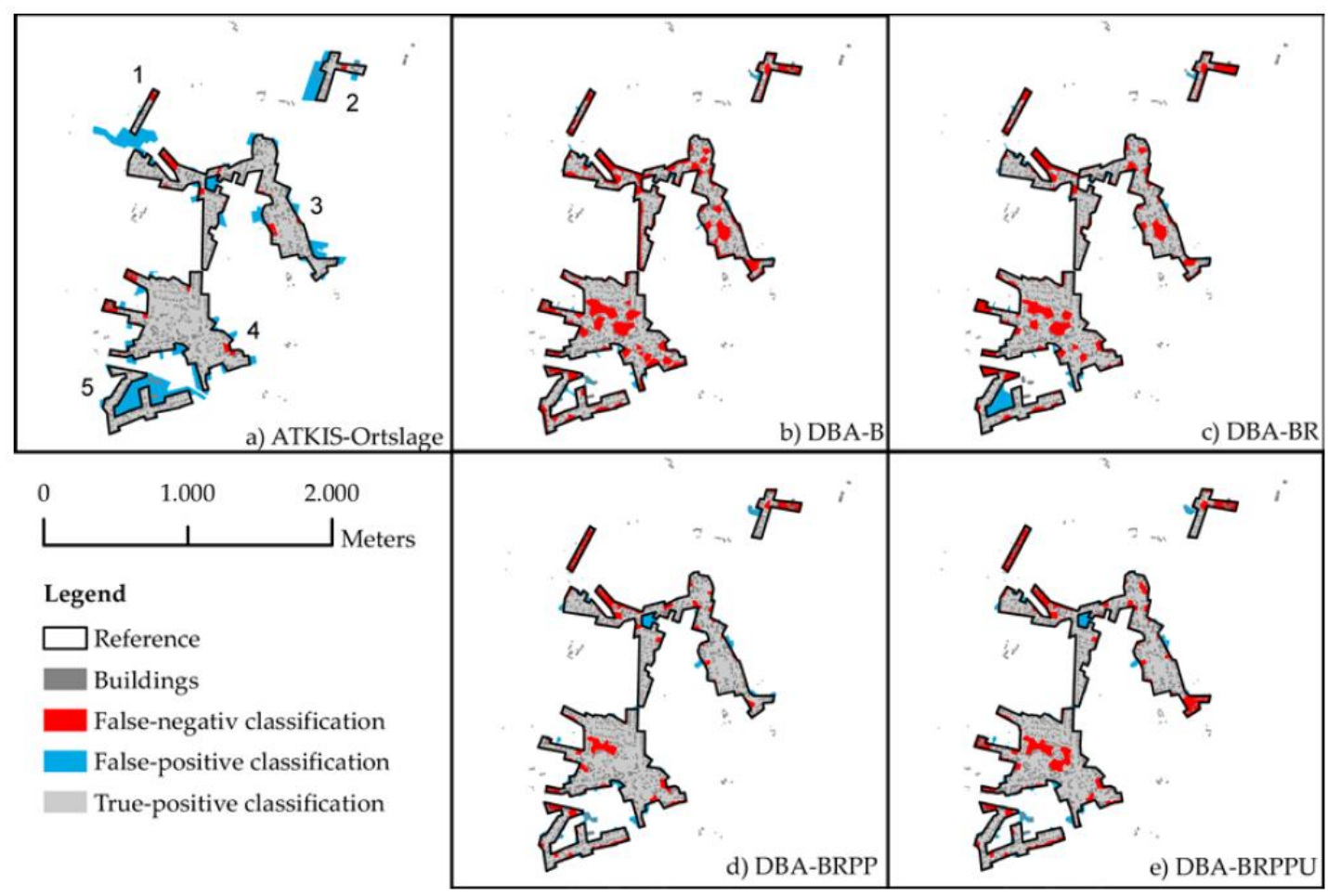

Figure 7. Examples of optimized boundaries of the: (a) ATKIS ${ }^{\circledR}$-Ortslage; (b) variant DBA-B; (c) variant DBA-BR; (d) variant DBA-BRPP; and (e) variant DBA-BRPPU (Official building polygons, ATKIS $^{\circledR}$ Base-DLM@ Geobasis-DE/BKG (2011)).

\subsection{Types of Error}

After measuring geometric quality as well as classification accuracy, two questions remain to be answered. What are the errors like? What are their frequency and their influence on the delineation 
accuracy (weighting)? This type of assessment depends on the content behind the specific boundary. It will therefore only relate to the specific application, is subjective and only partially generalizable. However, it will be briefly explained in the following for the sake of completeness and transparency as well as to demonstrate the limits of automation in the context of delineating built-up areas.

During automated generalization, systemic and data-induced errors may occur. The systemic errors are errors in the delineation that have their roots in the algorithm itself. False-negative classifications are gaps on the edge (cf. Figure $8 \mathrm{a}, \mathrm{f}$ ), empty spaces within a boundary (cf. Figure $7 \mathrm{~b}, \mathrm{c}$ ), edges that are not simplified (cf. Figure 8g) or line-like settlement structures that are not classified. False-positive classifications occur where single buildings are included within the boundary that are not formally assigned to the inner zone (cf. Figure $8 \mathrm{a}, \mathrm{c}, \mathrm{d}, \mathrm{f}, \mathrm{g}$ ). On the other hand, there are empty spaces within a boundary that cannot be recognized by the algorithm.

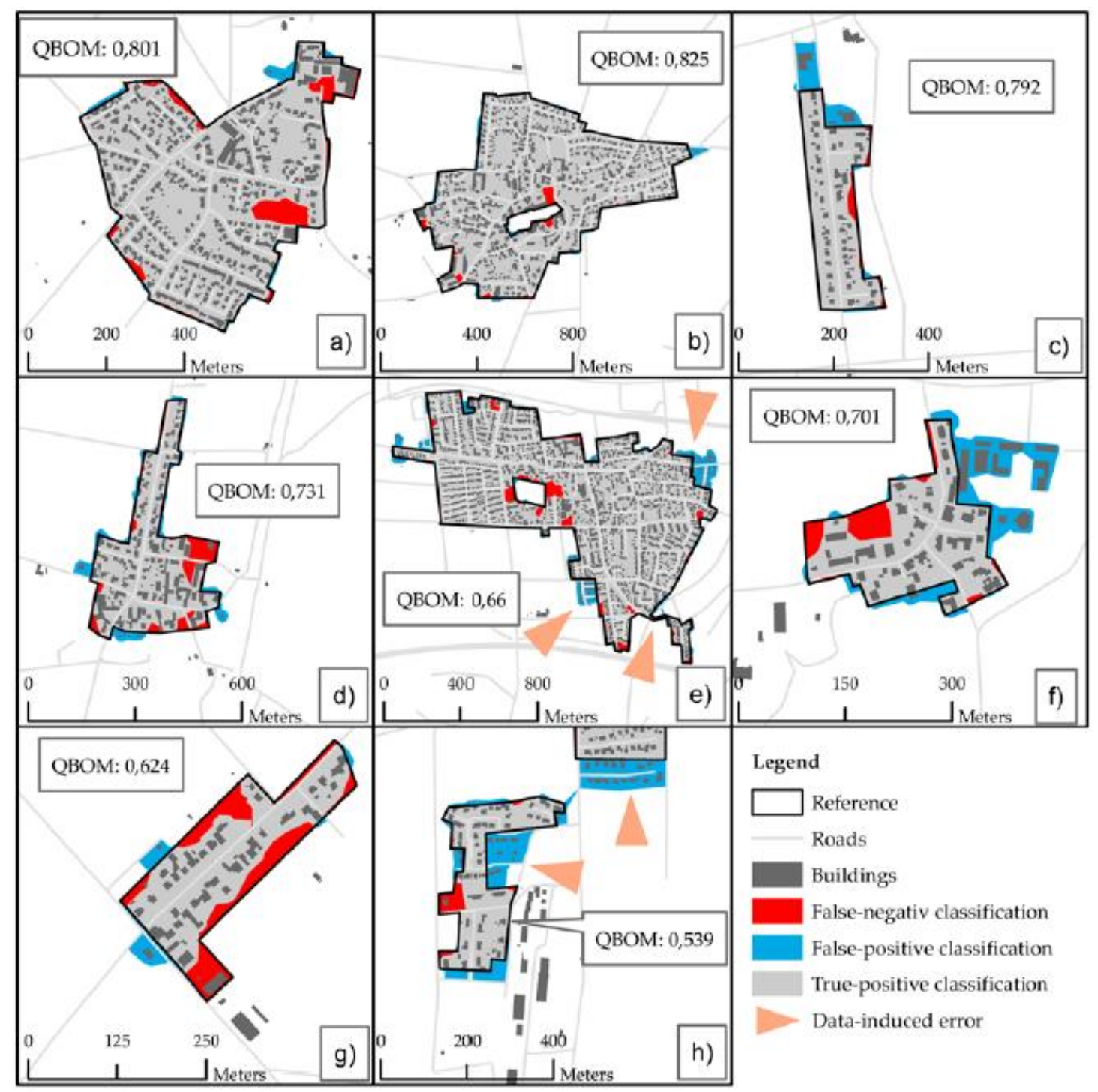

Figure 8. Examples of optimized boundaries relative to a reference, quality value $Q_{B O M}$ and classification results of variant DPA-BRPP (Official building polygons, ATKIS ${ }^{\circledR}$ Base-DLM CGeobasis-DE/BKG (2011)): settlement bodies of (a) Wilkenburg, (b) Jeinsen, (c) Gailhof, (d) Röddensen, (e) Godshorn, (f) Eckerde, (g) Klein Kolshorn and (h) Wehmingen

Data-induced errors are caused by errors in the input dataset. In this work, the use of data with different time slices (official building polygons from 2011 and reference data from 2005) cause errors 
due the changes in settlement structure that have taken place in the meantime. These are shown in Figure 8 e,h by arrows. The blue areas are examples of such settlement developments.

Another kind of data-introduced error comprises digitalization faults. For example, in Figure 8e, a digitized ridge can be seen that cannot be explained as to content.

Table 7 gives an overview of the frequency and weighting of errors in variant DBA-BRPP. The level of error has been evaluated on an ordinal scale from low to medium to high.

Table 7. Occurring errors and their qualitative assessment using the example of variant DBA-BRPP.

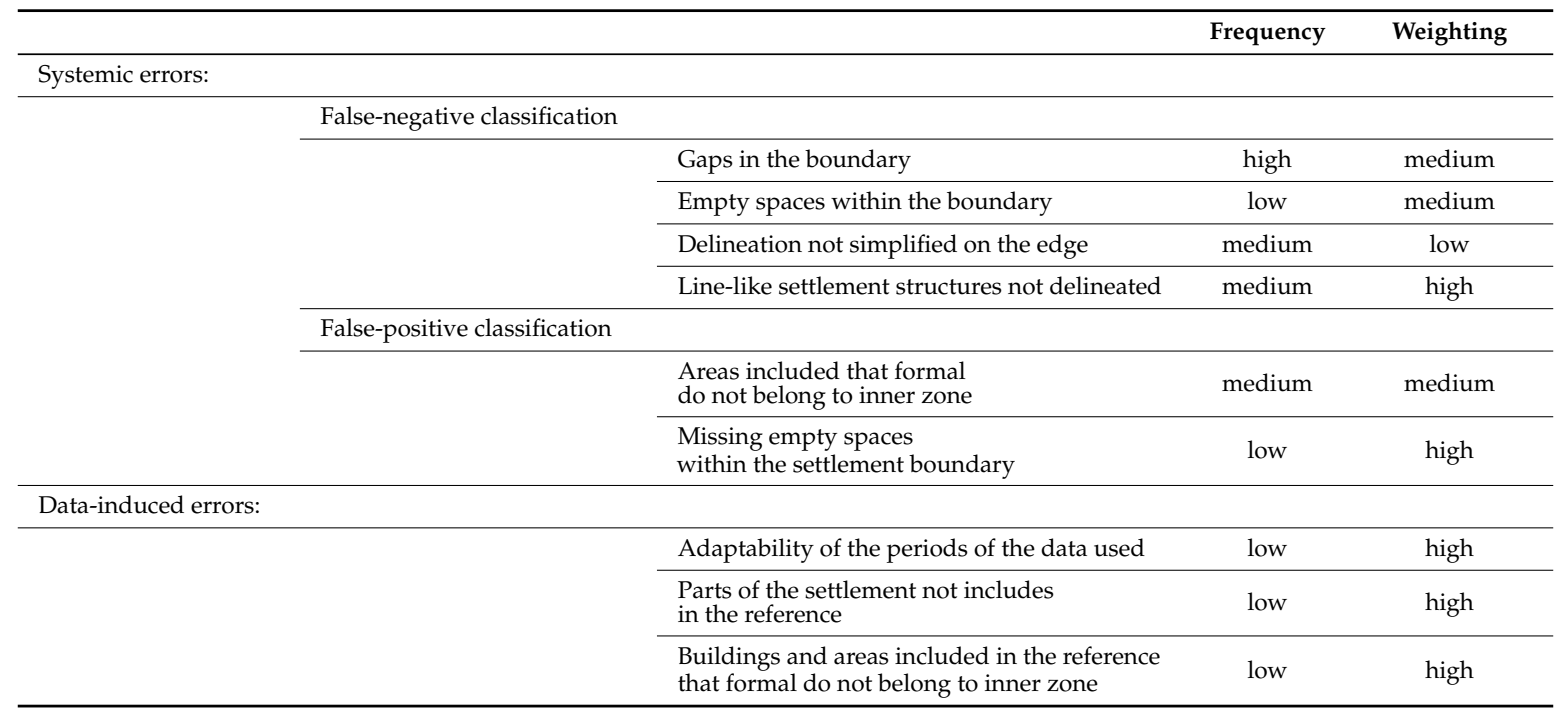

Errors with a combination of high or medium frequency and weighting have a high impact on the overall quality of the delineation. In this case, gaps at the edge of the boundary, missing delineations of line-like settlements and areas that do not formally belong to the inner zone are the problematic errors.

\section{Discussion}

In the following, the results are subjected to critical reflection against the backdrop of an application within a nationwide monitoring and analysis of settlements. Firstly, the different processing variants are discussed in terms of the accuracies achieved and in comparison to the previously used ATKIS ${ }^{\circledR}$-Ortslage. Secondly, the approach as a whole, using the best processing variant, is discussed from a practical point of view.

\subsection{Processing Variants}

\subsubsection{Variant DBA-B}

The results based on variant DBA-B with simple application of the Delineate Built-Up Area are not significantly better than the Ortslage from ATKIS ${ }^{\circledR}$ Base DLM in terms of the defined geometric quality measure $Q_{B O M}$. The classification accuracy shows a high number of false-positive features by count (cf. Table 5) but a look at the areas shows these features are mostly small settlement fragments in the outer zone. The high value for false negatives by area (cf. Table 6) is mainly caused by empty spaces resulting from undeveloped areas within the built-up area (e.g., parks, brownfields, and large parking areas). This is a problem Chaudhry and Mackaness [34] are facing with their buffer-based method as well as Chesnokova et al. [38] with the algorithm "Aggregate Polygons" from Esri's ArcGIS. Both solve this problem with additional post-processing steps, since from a practitioner's point of view these empty spaces should be closed and considered as built-up areas (inner zone). 


\subsubsection{Variant DBA-BR}

The quality of delineation can be significantly increased using variant DBA-BR, which considers roads as edges within the delineation process. This is obvious because the roads are often the real borders of a settlement and the introduction of these hard edges leads to a lower false-negative area, while slightly increasing the false-positive area. The introduction of roads has almost no effect on the precision and recall rate by count (cf. Table 5). Remarkable is the relatively high increase of $Q_{B O M}$ value to 0.679 .

\subsubsection{Variant DBA-BRPP}

Applying variant DBA-BRPP, which includes additional pre- and post-processing, the quality value $Q_{B O M}$ increases again significantly compared to the variant DBA-BR. The false-negative area could be reduced by eliminating and closing empty spaces and gaps in post-processing, but this occasionally creates new false-positive areas (see Table 6). A decrease in false-negative classification, 204 hectares $(4.36 \%)$, is opposed to a slight increase of 20 hectares of false-positives $(0.43 \%)$ in comparison to variant DBA-BR. In addition, the false positive features rate by number (cf. Table 5) was drastically reduced, leading to a considerable improvement of the overall precision rate to 0.96 . This is due mainly to the additional pre-processing, particularly the elimination of irrelevant buildings by filtering.

\subsubsection{Variant DBA-BRPPU}

In variant DBA-BRPPU, an additional urban index criterion is introduced with the aim of further reducing the false-positive features (e.g., Buildings for agricultural use) through filtering buildings in rural areas. The results show that the false-positives were in fact reduced by 51 hectares compared to variant DBA-BRPP but that at the same time an increase of false-negatives by 71 hectares was observed. It seems that the introduction of the urban index does not help adequately in discriminating the inner and outer zones. Overall, there is no significant increase or decrease of the $Q_{B O M}$ value in comparison to the previous variant DBA-BRPP.

\subsubsection{Comparison of Processing Variants}

The variants DBA-BRPP and DBA-BRPPU provide the best results in terms of the geometric quality represented by the $Q_{B O M}$ value and the classification accuracy (precision/recall). We therefore propose using variant DBA-BRPP, since the additional urban index calculation does not add value. For many classification problems, balanced values of false-positive and false-negative error are undesirable due to differences in the costs of error [39]. In our application case, underestimations are just as harmful as overestimations. In this variant, they are nearly the same, which can be considered a positive aspect.

In the application scenario of monitoring land take, the variant DBA-BRPP provides for better delineation than the Ortslage from ATKIS ${ }^{\circledR}$ Base DLM. Using the geometry from ATKIS ${ }^{\circledR}$ leads to an overestimation of the built-up area with a value of $27.5 \%$ compared to the reference, while applying our approach using variant DBA-BRPP the overestimation is only $0.15 \%$. However, for the evaluation of the delineation, precision and recall rate are also relevant. The values for both precision and recall are greater than 0.9 .

When interpreting precision and recall by area (Table 6), it needs to be mentioned that only small settlements are considered in this study. In this case, minor errors (false-positives or false-negatives) have a larger impact on the precision and recall rates than those within larger and more compact settlements. However, the introduced $Q_{B O M}$ value, as a quality measure, is independent of scale.

The variants DBA-B and DBA-BR do not providing a usable delineation due the high number of false-positive classifications. 


\subsection{Discussion of the Approach as a Whole}

The proposed partitioning algorithm presented in Section 3.1.1 has been proved useful within the overall approach in two ways. Firstly, it allows the partitioning of the building data for more efficient processing. Secondly, it is the basis for the partitioning of the data set into test and training data for the 10-fold cross-validation.

The introduced supervised learning approach was exemplary demonstrated using different processing variants that are based on a delineation algorithm available in Esri's ArcGIS for Desktop. In order to achieve the best applicability we chose ArcGIS for Desktop as it is often used in many planning offices and research institutes. Otherwise, a drawback of using commercial software products is that the delineation algorithm is not very well documented. Therefore, other delineation algorithms may be tested in future.

The algorithm for parameter optimization functions reliably and is easy to implement. However, its limits may be reached when the delineation algorithm used becomes more complex and more than two parameters need to be trained. For instance, using a brute-force method to search for the best parameter combination in a 10-dimensional parameter space would here increase the required number of computations dramatically. In the context of supervised machine learning, there exist many algorithms that allow an optimization of computations [40]. Another disadvantage is that the search is limited to a predefined number of parameter combinations due to the fact that the start point, the end point and the interval are predefined.

The choice of evaluation algorithm plays a key role. First, to be able to evaluate the respective delimitation results, it must consider both the geometric and the contextual aspects. The challenge is that comparing $\mathrm{n}$ fragmented polygons with $\mathrm{n}$ fragmented polygons has to produce reliable results. The vast majority of distance-based methods fail here [41]. Region-based methods, however, such as symmetric difference or area of overlap, often have a scale problem of their own. The BOM-algorithm can handle both problems. Second, the evaluation algorithm itself affects the delineation result. This is a general problem of all types of evaluation algorithm used for controlling evaluations. In this example, the small empty spaces in the variants are formed (minimization of parameter DET) due to the evaluation procedures as presented. The outer boundaries of a delineation are included in the assessment by using the buffer area of the reference (Area $R B)$ for normalizing only. Empty spaces within a delineation can be disregarded. This could be reduced by normalization with the buffer area of delineation (Area $D B$ ). However, this also means that the grouping distance as well as the length of the edges of a resultant polygon would increase. This in turn means that there would be more false classifications. This study is designed to recreate the boundary of the inner area and the closure of empty spaces that appear within a geometry based on characteristics such as size or shape, which are much easier to rework than the outer delimitation based on constraints. For this reason, normalization with the buffered reference is preferred. A further advantage in normalizing against the reference is that the variants are comparable to each other, since the reference in contrast to the delineation is constant. As a result of this conflict, we recommend for future research using two different versions of the evaluation algorithm: one for training using Area $D B$ for normalization and one for validation using Area $R B$ for normalization.

The selection of the training data is also important. Mustiere [42] identifies two major problems associated with reference data: The "[..] potential examples are not available in a suitable form; and they do not represent exact examples of what we intend to do". He solves this problem by creating the training data. However, this is not possible for many others working with supervised approaches, since the data acquisition is often not feasible. Here the view is that working with incomplete data or incorrect data is the rule rather than the exception and therefore attempts should be made to achieve the best possible solution under the circumstances. This also contributes to better later applicability and transferability. The error observed here in the training data lead to a devaluation of delineation quality, but have very little influence on the determination of the optimum parametric combination.

Experiments with the urban index have shown that the use of geometric filters reaches its limits when trying to derive semantic characteristics. A possible solution could be the introduction of a 
building classification approach $[35,43]$. A semantic enrichment of the data would help to eliminate the right buildings.

The transferability has to be discussed in three levels: (a) the transferability of the gained parameters by the reference data for another area in the same field of application; (b) the transferability of the algorithm with the use of new reference data to same field of application; and (c) the transferability of the entire approach to a different field of application.

At level (a), an imported precondition is that the settlement structure of the area in question is similar to the training area. The main challenge here is the necessity to define which settlements are similar. Recent research in the field of morphology of settlements could be helpful to solve this problem. For settlements with a very different morphology, a new training is necessary. This is level (b), where constraints are missing reference data. On level (c), the limitation is that, e.g., a different aggregation algorithm or field of application implies a new parameterization of the whole algorithm and not only a new training. Further research is planned in terms of the transferability to other areas-spatially and thematically. First experiments are promising but not the subject matter of this paper.

\subsection{Potential Applications}

The resulting geometry is mainly to be deployed for the automatic assessment of regional or interregional in-fill development potentials. Thus, at first this geometry is an input data for further calculations. For example, a delineation can be used to check whether the construction activities take place primarily, in the inner zone and not beyond the city boundaries. It is also a key date for calculation of connected indicators such as the ratio of inner/outer zone development [44]. The potential usage of inner zones in regional planning is diverse. In the Hessian regional plans, e.g., land take is controlled and limited as well in quantitative terms by quotas for building land as in qualitative terms by cartographic presentation $[36,45]$. For the calculation of the quotas as well as for the maps inner zones are needed (level (a) to (b), cf. 5.2).

However, even in the context of the development and testing of new planning instruments, like building certificates, the inner zone plays an important role $[46,47]$. In order to strengthen the primacy of in-fill development over development on the urban fringes and to promote the development of integrated urban areas, there is the initial necessity to define a geometry of the inner zone. Within this geometry, all projects are exempt from the requirement of building certificate (level (b) to (c)).

Finally, the approach is from a scientific point of view relevant because it provides an opportunity to reconstruct efficient historical settlement developments. Approaches for automatic building extraction [48] and building block extraction [49] based on topographic maps already exist. With the automatic delineation of settlement boundaries urban dynamics such as densification, growth and sprawl, or shrinkage can be examined on different scales and used as input data for simulations (level (c)).

\section{Conclusions}

We presented a supervised approach for the automatic delineation of settlement boundaries representing urban inner. The approach is set upon authoritative topographic data, particularly commonly available building footprint and road network data. A central component of the approach is the parameter optimization. Here, parameters of a defined delineation algorithm are trained in a supervised learning process using a suitable quality measure. For training and testing, a set of 166 official inner zone boundaries within the Hanover region in Germany is used. Experts have mapped those boundaries manually. During the development of the delineation process, four different process variants are tested and compared in terms of the achieved accuracies. All of them make use of standard geoprocessing functions implemented in ArcGIS for Desktop. The results of the variant DBA-B shows no significant increase of the value of $Q_{B O M}$, and, in variant DBA-BR, 
there are many false-negative classifications. Therefore both delineations could not be used for a monitoring application.

The processing variant DBA-BRPP was identified as the best variant. This approach leads to a balanced precision and recall rate of approximately 0.9 and a mean value of the $Q_{B O M}$ quality measure of 0.71 . Compared to the previously used settlement boundaries of the ATKIS ${ }^{\circledR}$ DLM, the quality of the delineation using the proposed approach is significantly higher.

Therefore the results of the proposed approach are promising and can support several land use monitoring processes in the context of planning and policy making (e.g., monitoring, decision support, land take management and evaluation of planning instruments). In particular, in the debates about preserving valuable soils and achieving the policy goals (reduction of greenfield development, and zero net land take in 2050 in the EU), approaches for quantification are needed. Automatically delineated settlement boundaries from common topographic data can contribute to the challenge of measuring the settlement development in high resolution.

Acknowledgments: The study was realized at the Leibniz Institute of Ecological Urban and Regional Development (IOER) with the assistance of the Institute for Cartography of Dresden University of Technology. All mentioned official spatial base data were at the disposal of the IOER for the purposes of research. The authors would like to thank the Federal Agency for Cartography and Geodesy (Bundesamt für Kartographie und Geodäsie, BKG), the Central Distribution Agency for House Coordinates, Building Polygons and 3D Building and Ms. Gügel from Hanover Region for the provision of this data. Further, the authors would like to thank Gotthard Meinel and colleagues at IOER for their support. The publication of this article was funded by the Open Access fund of the Leibniz Association.

Author Contributions: Oliver Harig developed the approach together with Robert Hecht. Oliver Harig implemented the procedure, analyzed the data and wrote the initial manuscript. Robert Hecht served as the subject advisor for this work, discussed the approach, revised the structure of the manuscript and mainly contributed to Sections 1, 2 and 5. Dirk Burckhardt as the doctoral advisor contributed to discussing the results and providing a proof-reading that substantially improved the manuscript.

Conflicts of Interest: The authors declare no conflict of interest.

\section{References}

1. Jaeger, J.A.; Bertiller, R.; Schwick, C.; Cavens, D.; Kienast, F. Urban permeation of landscapes and sprawl per capita: New measures of urban sprawl. Ecol. Indic. 2010, 10, 427-441. [CrossRef]

2. Siedentop, S.; Fina, S. Monitoring urban sprawl in Germany: Towards a GIS-based measurement and assessment approach. J. Land Use Sci. 2010, 5, 73-104. [CrossRef]

3. Decoville, A.; Schneider, M. Can the 2050 zero land take objective of the EU be reliably monitored? A comparative study. J. Land Use Sci. 2016, 11, 331-349. [CrossRef]

4. Zhou, Q. Comparative study of approaches to delineating built-up areas using road network data. Trans. GIS 2015, 19, 848-876. [CrossRef]

5. Longley, P.A.; Mesev, V. On the measurement and generalisation of urban form. Environ. Plan. A 2000, 32, 473-488. [CrossRef]

6. Mesev, V. Urban morphology reconstruction: links between satellite imagery and address information. In GIS and Evidence-Based Policy Making; Taylor \& Francis: London, UK, 2010; pp. 9-42.

7. Heikkila, E.J.; Shen, T.; Yang, K. Fuzzy urban sets: Theory and application to Desakota regions in China. Environ. Plan. B Plan. Des. 2003, 30, 239-254. [CrossRef]

8. Zhou, Y.; Smith, S.J.; Elvidge, C.D.; Zhao, K.; Thomson, A.; Imhoff, M. A cluster-based method to map urban area from DMSP/OLS nightlights. Remote Sens. Environ. 2014, 147, 173-185. [CrossRef]

9. Walter, V. Automatic Interpretation of Vector Databases with a Raster-Based Algorithm. Int. Arch. Photogramm. Remote Sens. Spat. Inf. Sci. 2008, 37 (Part B2), 175-181.

10. Hangouët, J.-F. Approche et Méthodes Pour L'automatisation de la Généralisation Cartographique; Application en Bord de Ville. Ph.D. Thesis, Université de Marne-La-Vallée, hamps-sur-Marne, France, 1998.

11. Regnauld, N. Généralisation du Bâti: Structure Spatiale de Type Graphe et Représentation Cartographique. Ph.D. Thesis, Provence University, Marseille, France, 1998.

12. Regnauld, N. Contextual building typification in automated map generalization. Algorithmica 2001, 30, 312-333. [CrossRef] 
13. Wertheimer, M. Untersuchungen zur Lehre von der Gestalt. II. Psychol. Res. 1923, 4, 301-350. [CrossRef]

14. Boffet, A.; Serra, S.R. Identification of spatial structures within urban blocks for town characterization. In Proceedings of the 20th International Cartographic Conference, Beijing, China, 6-10 August 2001; pp. 1974-1983.

15. Christophe, S.; Ruas, A. Detecting building alignments for generalisation purposes. In Advances in Geographic Information Science; Springer: Berlin, Germany, 2002; pp. 419-432.

16. Yan, H.; Weibel, R.; Yang, B. A Multi-parameter approach to automated building grouping and generalization. Geoinformatica 2008, 12, 73-89. [CrossRef]

17. Li, Z.; Yan, H.; Ai, T.; Chen, J. Automated building generalization based on urban morphology and gestalt theory. Int. J. Geogr. Inf. Sci. 2004, 18, 513-534. [CrossRef]

18. Chaudhry, O.; Mackaness, W.A. automatic identification of urban settlement boundaries for multiple representation databases. Comput. Environ. Urban Syst. 2008, 32, 95-109. [CrossRef]

19. Bundesregierung Perspectives for Germany: Our Strategy for Sustainable Development. Available online: https://www.nachhaltigkeitsrat.de/fileadmin/user_upload/English/pdf/Perspectives_for_Germany. pdf (accessed on 23 April 2016).

20. European Commission. The Roadmap to a Resource Efficient Europe (COM (2011) 571). Available online: http:/ / eur-lex.europa.eu/legal-content/EN/TXT/PDF/?uri=CELEX:52011DC0571\&from=EN (accessed on 23 April 2016).

21. Science for Environment Policy: No Net Land Take by 2050? Future Brief 14. Produced for the European Commission DG Environment by the Science Communication Unit, UWE, Bristol. Available online: http: / / ec.europa.eu/science-environment-policy (accessed on 3 August 2016).

22. Battis, U.; Krautzberger, M.; Löhr, R.-P. Baugesetzbuch/BauGB; C.H. Beck: Munich, Germany, 2009.

23. Brügelmann, H.; Dürr, H.; Bank, W.J.; Korbmacher, A. Baugesetzbuch/Kommentar; Kohlhammer: Stuttgart, Germany, 2011.

24. Schiller, G.; Blum, A.; Hecht, R.; Meinel, G.; Oertel, H.; Ferber, U.; Petermann, E. Innenentwicklungspotenziale in Deutschland: Ergebnisse einer bundesweiten Umfrage und Möglichkeiten einer automatisierten Abschätzung; Bundesinstitut für Bau-, Stadt-und Raumforschung (BBSR) im Bundesamt für Bauwesen und Raumordnung (BBR): Bonn, Germany, 2013.

25. Elgendy, H.; Michels, S. Raum+ Rheinland-Pfalz 2010: Die Bewertung von Flächenpotenzialen für eine zukunftsfähige Siedlungsentwicklung; Ministerium für Wirtschaft, Energie, Klimaschutz und Landesplanung: Mainz, Germany, 2011.

26. AdV AdV Dokumentation zur Modellierung der Geoinformationen des amtlichen Vermessungswesens (GeoInfoDok)—Erläuterungen zu ALKIS ${ }^{\circledR}$. Version 6.0.1; Arbeitsgemeinschaft der Vermessungsverwaltungen der Länder der Bundesrepublik Deutschland: Germany, 2008.

27. Schiller, G.; Oertel, H.; Blum, A. Innenentwicklungspotenziale in Deutschland-Ergebnisse einer bundesweiten Befragung. In Flächennutzungsmonitoring $V$ - Methodik, Analyseergebnisse, Flächenmanagement; Rhombos: Berlin, Germany, 2013; pp. 51-59.

28. ArcGIS Resources Delineate Built-Up Areas. Available online: http://resources.arcgis.com/en/help/main/ 10.1/index.html\#/ / 007000000047000000 (accessed on 23 April 2016).

29. Alpaydin, E. Introduction to Machine Learning; The MIT Press: Cambridge, MA, USA, 2010.

30. ArcGIS Resources How Line Density Works. Available online: http://resources.arcgis.com/en/help/main/ 10.1/index.html\#/How_Line_Density_works/009z00000012000000/ (accessed on 23 April 2016).

31. Mackaness, W.A.; Ruas, A. Evaluation in Map Generalisation Process. In Generalisation of Geographic Information: Cartographic Modelling and Applications; Sarjakoski, L.T., Ruas, A., Mackaness, W., Eds.; Elsevier: Oxford, UK, 2007; pp. 89-112.

32. Tveite, H.; Langaas, S. An accuracy assessment method for geographical line data sets based on buffering. Int. J. Geogr. Inf. Sci. 1999, 13, 27-47. [CrossRef]

33. Vetter, A.; Wigley, M.; Käuferle, D.; Gartner, G. The automatic generalisation of building polygons with arcGIS standard tools based on the 1:50,000 Swiss National Map Series. In Proceedings of the 18th ICA Workshop on Generalisation and Multiple Representation, Rio de Janeiro, Brazil, 21 August 2015.

34. Chaudhry, O.; Mackaness, W. Visualisation of settlements over large changes in scale. In Proceedings of the 9th ICA Workshop on Generalisation and Multiple Representation, La Coruña, Spain, 7-8 July 2005. 
35. Hecht, R.; Meinel, G.; Buchroithner, M.F. Automatic identification of building types based on topographic databases-A comparison of different data sources. Int. J. Cartogr. 2015. [CrossRef]

36. Mas, J.-F.; Soares Filho, B.; Pontius, R.G.; Farfán Gutiérrez, M.; Rodrigues, H. A suite of tools for ROC analysis of spatial models. ISPRS Int. J. Geo Inf. 2013, 2, 869-887. [CrossRef]

37. Bukies, K.; Meyer, H.; Rabe, E. Die Ermittlung der praktischen Grundlagen für die Festlegungen im Regionalen Raumordnungsprogramm 2005. In Steuerung der Eigenentwicklung in Ländlichen Siedlungen-Baustein Einer Nachhaltigen Flächenhaushaltspolitik; Beiträge zur regionalen Entwicklung; 123, Region Hannover: Hanover, Germany, 2009; pp. 29-43.

38. Chesnokova, O.; Buffat, R.; Sieber, R.; Hurni, L. Depicting settlement development-extraction and visualization workflow. In Proceedings of the 27th International Cartographic Conference-16th General Assembly, Rio de Janeiro, Brazil, 23-28 August 2015.

39. Provost, F.J;; Fawcett, T.; Kohavi, R. The case against accuracy estimation for comparing induction algorithms. In Proceedings of the ICML 5th International Conference on Machine Learning, San Francisco, CA, USA, 24-27 July 1998.

40. Kotsiantis, S.B.; Zaharakis, I.; Pintelas, P. Supervised machine learning: A review of classification techniques. Informatica 2007, 31, 249-268.

41. Hagedoorn, M.; Veltkamp, R.C. State of the art in shape matching. In Principles of Visual Information Retrieval; Advances in Pattern Recognition; Springer: Berlin, Germany, 2001; pp. 87-119.

42. Mustière, S. Cartographic generalization of roads in a local and adaptive approach: A knowledge acquistion problem. Int. J. Geogr. Inf. Sci. 2005, 19, 937-955. [CrossRef]

43. Steiniger, S.; Lange, T.; Burghardt, D.; Weibel, R. An Approach for the Classification of Urban Building Structures Based on Discriminant Analysis Techniques. Trans. GIS 2008, 12, 31-59. [CrossRef]

44. Meinel, G.; Hecht, R.; Herold, H. Analyzing building stock using topographic maps and GIS. Build. Res. Inf. 2009, 37, 468-482. [CrossRef]

45. Bovet, J. Handelbare Flächenausweisungsrechte als Steuerungsinstrument zur Reduzierung der Flächeninanspruchnahme. Nat. Recht 2006, 28, 473-479. [CrossRef]

46. Henger, R.; Bizer, K. Tradable planning permits for land-use control in Germany. Land Use Policy 2010, 27, 843-852. [CrossRef]

47. Schmidt, T. Innenentwicklungsbereich und Zertifikatpflicht; Flächenhandel-Informationspapier Nr. 3; Büro für Standortplanung Hamburg: Hamburg, Germany, 2014.

48. Herold, H. An Evolutionary Approach to Adaptive Image Analysis for Retrieving and Long-Term Monitoring Historical Land Use from Spatiotemporally Heterogeneous Map Sources. Ph.D. Thesis, Dresden University of Technology, Dresden, Germany, 2015.

49. Muhs, S.; Herold, H.; Meinel, G.; Burghardt, D.; Kretschmer, O. Automatic delineation of built-up area at urban block level from topographic maps. Comput. Environ. Urban Syst. 2016, 58, 71-84. [CrossRef] 